
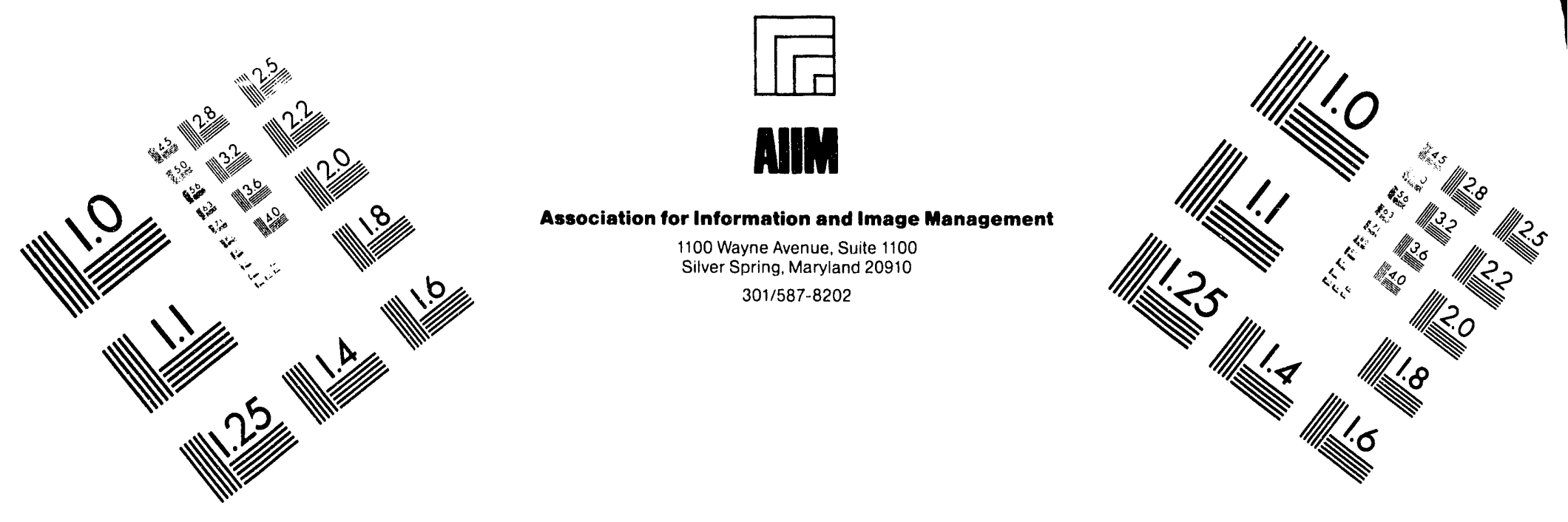

\title{
Centimeter
}

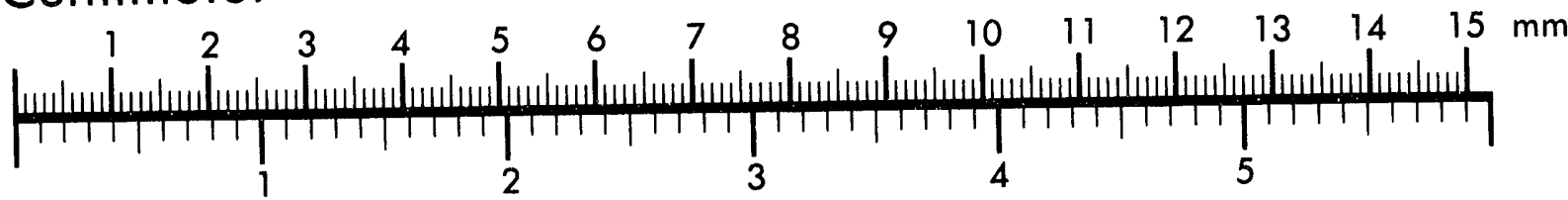
Inches
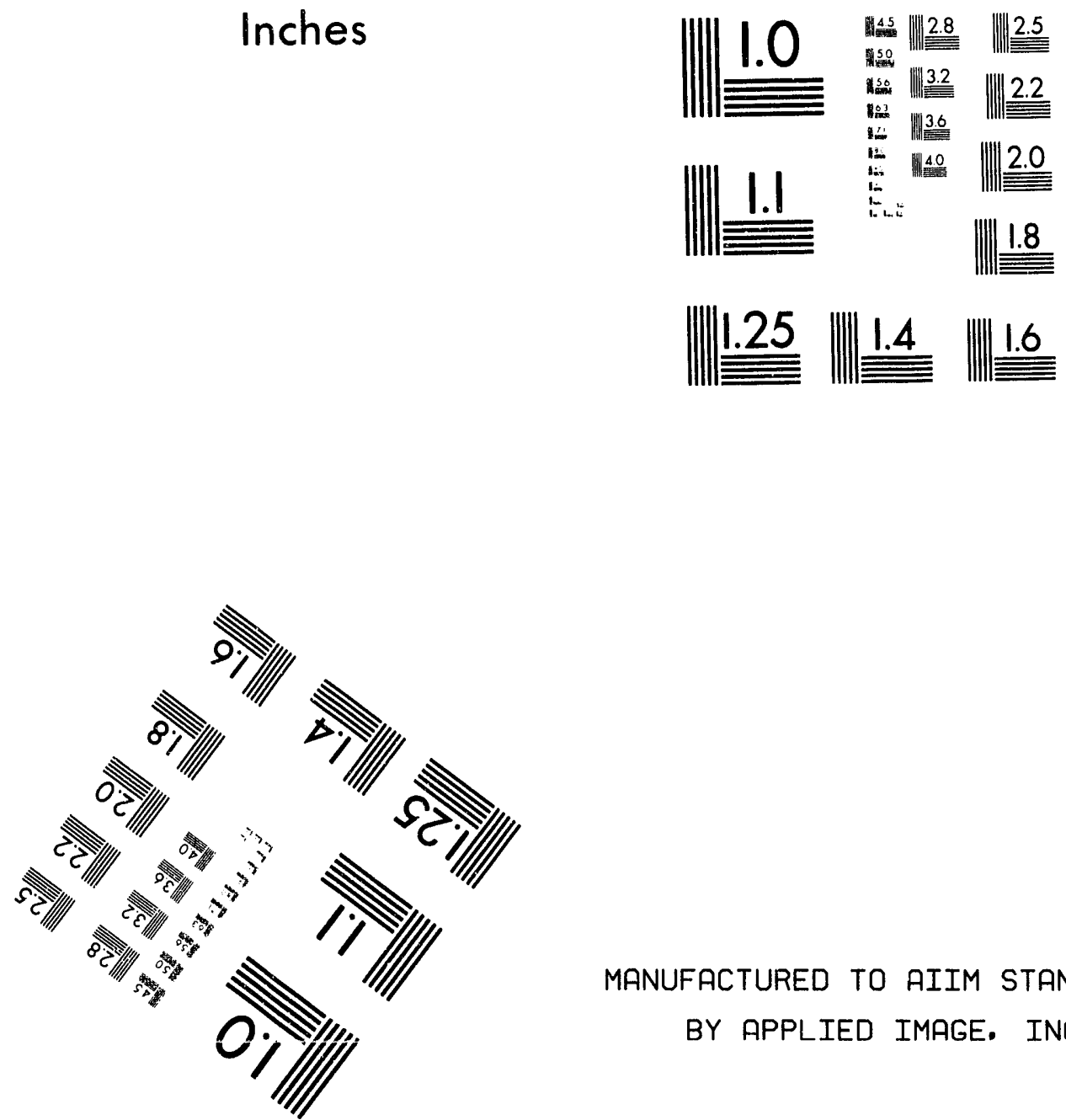

MANUFACTURED TO AIIM STANDARDS

BY APPLIED IMAGE. INC.

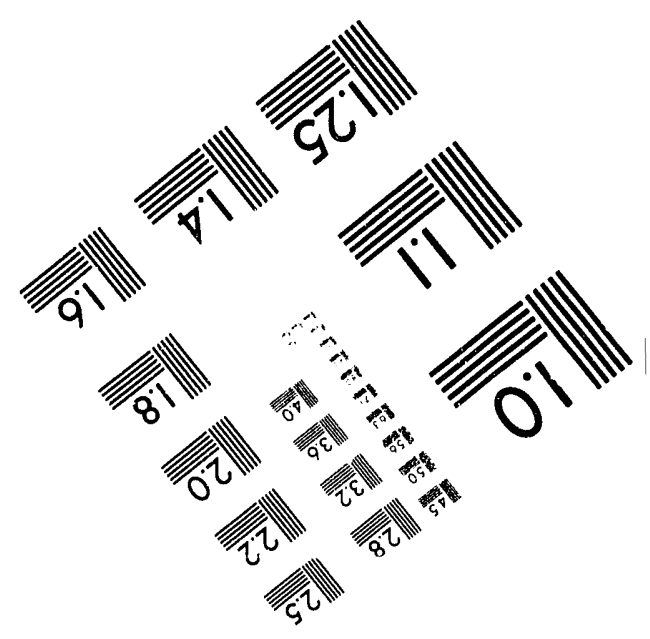



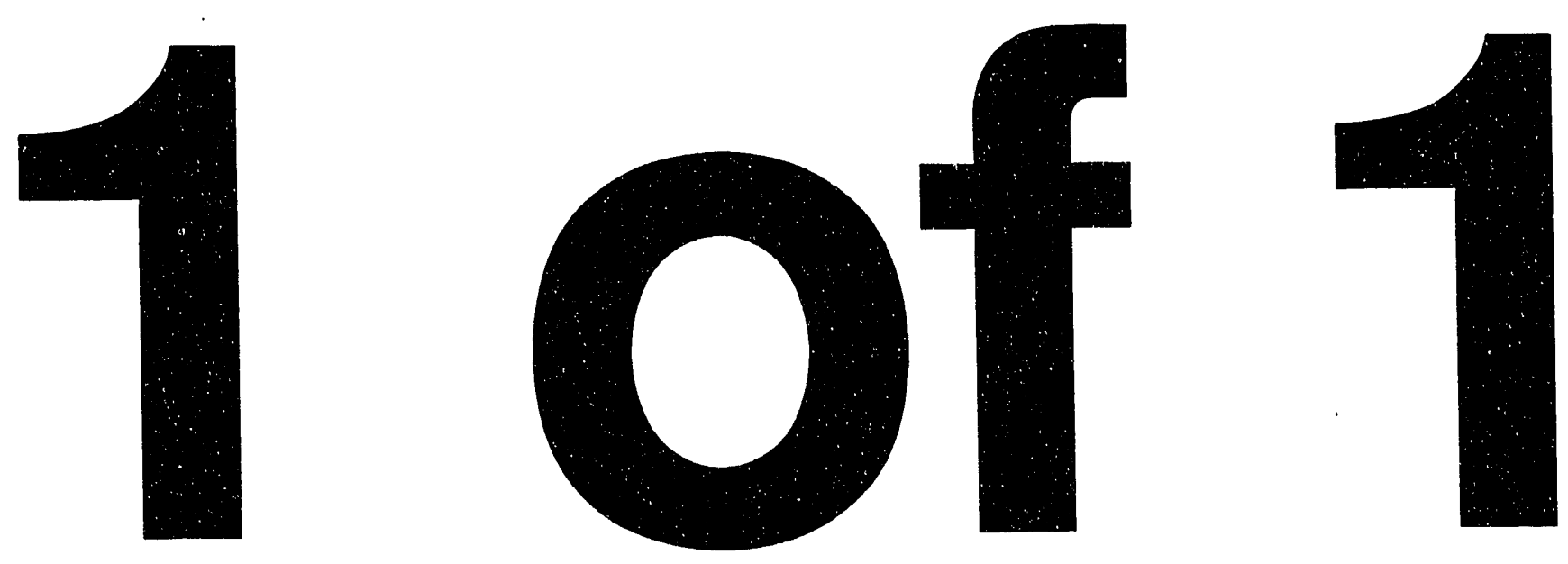


\title{
Sequestering Carbon Dioxide in Industrial Polymers:
}

\section{Building Materials for the 21st Century}

\author{
P. M. Molton \\ D. A. Nelson
}

June 1993

Prepared for the U.S. Department of Energy under Contract DE-AC06-76RLO 1830

Pacific Northwest Laboratory

Richland, Washington 99352 


\section{Summary}

This study was undertaken to determine the possibility of developing beneficial uses for carbon dioxide as a key component for a largevolume building product. Such a use may provide an alternative to storing the gas in oceanic sinks or clathrates as a way to slow the rate of global warming. Silica (poly-silicon dioxide) is used worldwide in construction as a basic, major component of building materials from concrete to mud; wood (lumber) is the other major building material.

We investigated the concept that carbon dioxide might be used with other chemicals to make carbon-dioxide-based polymers which would be lightweight, strong, and economical alternatives to some types of wood and silica-based building materials. As a construction-grade material, carbon dioxide would be fixed in a solid, useful form where it would not contribute to global warming. With the probable imposition of a fuel carbon tax in industrialized countries, including the United States, this alternative would allow beneficial use of the carbon dioxide and could remove it from the tax basis if legislation were structured appropriately. Hence, there would be an economic driver towards the use of carbon-dioxide-based polymers which would enhance their future applications.

We obtained information through literature searches and personal contacts on carbon dioxide polymers which showed that the concept 1) is technically feasible, 2) is economically defensible, and 3) has an existing industrial infrastructure which could logically develop it. The technology exists for production of building materials which are strong enough for use by industry and which contain up to $90 \%$ by weight of carbon dioxide, both chemically and physically bound. A significant side-benefit of using this material would be that it is selfextinguishing in case of fire.

This report is the first stage in the investigation. Further work being proposed will provide details on costs, specific applications and volumes, and potential impacts of this technology. 


\section{Cuntents}

Summary $\ldots \ldots \ldots \ldots \ldots \ldots \ldots \ldots \ldots \ldots \ldots \ldots \ldots \ldots \ldots \ldots \ldots \ldots \ldots$

Introduction $\ldots \ldots \ldots \ldots \ldots \ldots \ldots \ldots \ldots \ldots \ldots \ldots \ldots \ldots \ldots \ldots$

Rationale for Using Carbon Dioxide $\ldots \ldots \ldots \ldots \ldots \ldots \ldots \ldots \ldots \ldots \ldots \ldots$

Carbon Dioxide Chemistry $\ldots \ldots \ldots \ldots \ldots \ldots \ldots \ldots \ldots \ldots \ldots \ldots$

Potential Uses for Carbon Dioxide in Polymers and Basic Chemicals . . . . . . . . . 11

Carbon Dioxide as a Chemical Feedstock $\ldots \ldots \ldots \ldots \ldots \ldots \ldots \ldots$

Polymers $\ldots \ldots \ldots \ldots \ldots \ldots \ldots \ldots \ldots \ldots \ldots \ldots \ldots \ldots \ldots \ldots \ldots$

Agricultural Chemicals $\ldots \ldots \ldots \ldots \ldots \ldots \ldots \ldots \ldots \ldots \ldots \ldots \ldots$

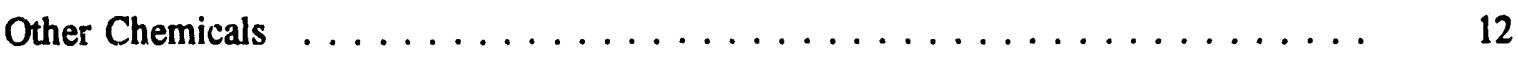

Properties and Uses of Carbon-Dioxide-Based Polymers $\ldots \ldots \ldots \ldots$

Polyalkylene Carbonates . . . . . . . . . . . . . . . . . . . 12

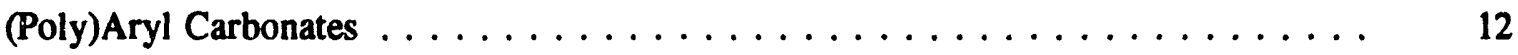

Polyureas $\ldots \ldots \ldots \ldots \ldots \ldots \ldots \ldots \ldots \ldots \ldots \ldots \ldots \ldots \ldots \ldots \ldots$

Polyurethanes $\ldots \ldots \ldots \ldots \ldots \ldots \ldots \ldots \ldots \ldots \ldots \ldots \ldots \ldots \ldots \ldots$

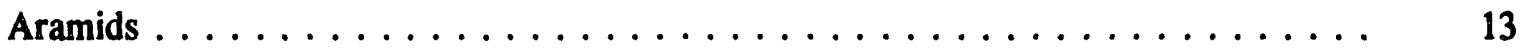

Other Polymers $\ldots \ldots \ldots \ldots \ldots \ldots \ldots \ldots \ldots \ldots \ldots \ldots \ldots \ldots \ldots$

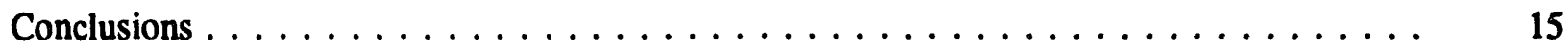

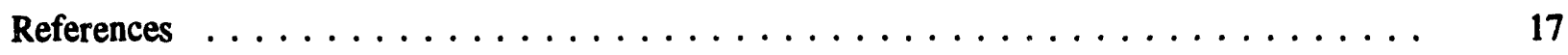

Bibliography $\ldots \ldots \ldots \ldots \ldots \ldots \ldots \ldots \ldots \ldots \ldots \ldots \ldots \ldots \ldots \ldots \ldots$ 


\section{Introduction}

Modern building materials in use in the United States comprise brick and concrete, steel and aluminum, wood, and small amounts of plastics. The more specialized uses for materials-steel and aluminum for structural strength and copper in pipes, for example-are unlikely to be replaced by plastics in the near future. However, brick, concrete and wood are potential candidates for replacement. In the East, houses are made primarily of brick and concrete mostly because they are good thermal insulators and are resistant to insect attack. They are relatively heavy and expensive compared with wood, which is the building material of choice in the West. Production of brick and cement used in concrete is energy-intensive, while environmental concerns (over-logging, clearcutting, and the spotted owl) have caused major problems in the lumber industry. Carbon dioxide by contrast is a waste gas which is produced from energy generation. It will never be in short supply, and its removal from the atmospheric sink is environmentally desirable.

The trend away from "pure" wood products in building is already apparent. Construction in the United States, is moving toward more use of chip board, exterior composite siding and shingle composites, as well as multi-2 $\times 6$ wood composites in place of $6 \times 10$ wood supports for the structure's load-bearing regions. Gypsum wallboard has effectively replaced plaster for interior wall coverings and is ready itself to be replaced by polymer-based panels. The polymer in most of these materials is phenol-formaldehyde or resorcinol-formaldehyde resin and is already economically competitive with wood. There has been some attempt to introduce polymer lumber into the building trade, but price and performance have hampered acceptance of the material so far. (This is no reflection on its quality. Since buildings are expected to last many years, the construction trade is very conservative with the use of new, unproven materials).

Dimensional lumber and especially load-bearing beams are the highest level materials used in construction. Carbon dioxide polymers that are cost- and performance-competitive to fir/spruce lumber should be rapidly accepted into construction commerce at all levels.

Various potential carbon-dioxide-based polymers exist and have their own niches in industrial society-polycarbonates in glass bottle substitutes, polyterephthalates in polyester clothing, and polyurethanes in foams are the most obvious current examples. The effort to use polycarbonate or other high carbon-dioxidecontaining polymers for dimensional lumber requires a product with a consistent composition and reproducible physical properties. In addition, the product must provide a direct substitution for a wood product and be produced at lower cost than wood.

Development of these materials would not be difficult and, in fact, is already in progress for high-value, non-building applications, such as aircraft parts. The consistent composition requirement involves knowledge of compatible fillers and the levels of individual components which can be varied without degrading desirable properties. A mixing aid might be required to alleviate phase separation if a dissimilar filler is used, or to render the product stable to oxidation and exposure to sunlight.

Reproducible physical properties will be the most difficult to achieve with an inexpensive polymeric starting material. Properties such as tensile strength and modulus may be controlled and enhanced to the level of spruce/fir by the 
use of high tensile filament inclusions. This would involve the use of glass fiber windings at specific dimension (depth) within the plastic product. Load-bearing material can make use of the Baroni beam concept. This geometric concept is quite applicable to polymeric materials.

A major finding of the initial research was the concept of including carbon dioxide gas into carbon-dioxide-based polymers. In the basic ethylene polycarbonate, about $50 \%$ of the weight of the polymer is chemically-bound carbon dioxide. Injection of carbon dioxide gas into the polymer produces a composite which has up to $90 \%$ by weight of carbon dioxide (chemically bound plus entrapped carbon dioxide) without significant degradation of polymer strength. To obtain such control of product density, one of two concepts may be applied. The first involves the use of sodium bicarbonate as a blowing agent at extrusion temperatures. The carbon dioxide produced can form a foamed product with lower density. However, good control of the foam can be more readily achieved with the results of Kumar et al. at the University of Washington (1990).

Kumar et al. pumped carbon dioxide under high pressure into polycarbonate to form a microcellular product with less density, but a definitely controlled bubble size (5-10 micrometer). This procedure allows for excellent retention of properties that can vary the density from $10-90 \%$ of original.

The final product must not require extra on-site processing or specialized equipment; i.e., nailing, sawing, drilling, etc., must use normal equipment and procedures. Carpenters are usually quite conservative; thus, one must be aware of current construction practices. A foamed or filled polymeric material should allow standard practices to be applied in a manner similar to that of wood.

With such a developed product, a 100 - to 1000 fold increase in the use of carbon-dioxide-based plastics in the next century could result in a significant reduction in the rate of global warming if the carbon dioxide is derived from fossil fuels. One should note that the organic monomers which are reacted with carbon dioxide to form the copolymers can themselves be made directly or indirectly from biomass rather than from fossil fuels.

If, indeed, the polymeric product can achieve low cost, it could provide building materials in the 21 st century, as well as provide an ecologically safe sink for carbon dioxide. 


\section{Rationale for Using Carbon Dioxide}

The concept of basing building materials on a gas is not intuitively obvious unless a number of existing societal factors are brought together. Also, the above discussion claims feasibility without providing evidence that carbon-dioxidebased polymers exist and have the potential for the uses identified. The following discussion provides the framework and evidence to support the claims and is based on 1) global warming, 2) world population growth, and 3) industry's need for a new, cheap raw material.

Carbon dioxide is a waste product of fossil fuel combustion; as such it is a potential raw material if it can be economically captured from the nitrogen and carbon dioxide combustion mix. Its cost would basically be equal to the cost of separation less any credit (via a carbon tax credit) for carbon not entering the atmosphere. Burning of fossil fuels currently adds 5.7 billion metric tons $(\mathrm{mt})$ of carbon to the atmosphere annually, and deforestation another 1.5 - 3 billion $\mathrm{mt}$ (Burton 1992).

The overall effects of this increase are difficult to predict, but are likely to include major perturbations in forest ecosystems, local rainfall, agriculture, and sea level. At one extreme, human civilization would become difficult to maintain, while at the other, benefits from global warming could be greater than the disadvantages (Hileman 1992) if the carbon dioxide causes accelerated plant growth. However, this is difficult to establish and one investigation on enhanced growth rates identified a number of other critical variables which could swamp the carbon dioxide fertilization effect (Pitelka 1992).

Although the effects of global warming are still being debated in the scientific community, it has been accepted as an established fact by millions of voters worldwide, and the cause has been identified with equal certainty as anthropogenic emissions, mostly from fossil fuel burning. Political decisions which have been made or are in process of being made may or may not reduce the rate of increase of carbon dioxide in the atmosphere, but will certainly impede technological and social progress. Such solutions as a carbon tax or pumping power plant emissions into deep water are being implemented with little understanding of their efficacy or consequences. For example, on November 1, 1990, the German federal government set a target of reducing carbon dioxide emissions by $25 \%$ by the year 2005 (Owen 1991), and other European and Scandinavian countries have set similar, although less stringent, goals.

With the current antinuclear stance precluding the obvious switch from fossil-fuel-based power systems to nuclear power, it is difficult to see how these goals can be achieved without severe cutbacks in energy production and disruption of industrial development in the United States.

If we accept that a net reduction or at least a slowing of the rate of increase in atmospheric carbon dioxide levels over the next century is a desirable goal, there are several possible ways of achieving this goal:

1. Produce less carbon dioxide through conservation or by developing non-fossil-based fuel sources.

2. Divert the carbon dioxide for a period of 100 to 1000 years into a non-atmospheric "sink" -in effect, returning it to fossil status.

3. Combine the carbon dioxide into useful and recyclable materials. 
Forced conservation and/or change to other fuels is, of course, the purpose of the "carbon tax" being considered by other countries. As a first step, such an approach will reap useful benefits since it will apply an economic driver to reduce waste and to develop other energy sources such as solar, nuclear, tidal, and hydroelectric. If implemented beyond this point, it will cause a severe restriction on world economic development by raising the cost of energy (Clarke 1991; Barfield et al. 1991).

The second option is also being considered; for example, increased biomass production through tree planting, which would also have the effect of producing biomass fuels. Direct deep injection of power plant combustion gases so that the carbon dioxide forms a water clathrate precipitate is being considered in Japan, but this simply wastes the carbon dioxide by removing it from the industrial scene. The advantage of these systems is that they do not require draconian reduction in fossil fuel burning.

In one future development scenario, maximizing efficiency of carbon use will occur first through conservation; use of combined heat and power systems (CHP) (Owen 1991); and development of remaining resources of hydroelectric, wind, tide, and nuclear systems. Technical developments may make efficient solar and possibly thermonuclear power available. In the meantime, the need to continue power production through fossil fuel combustion will require the use of oceanic sinks as an interim measure. Depletion of fossil fuels will ultimately require that the various chemical industries convert from oil and gas feedstocks to biomass. In any case, chemicals will always require a source of carbon. Biomass could be used as the basis for a modified chemical industry, since all of the basic carbon-based intermediates can be made from it. Biomass contains more oxygen than oil or gas and would simply require less oxidation. The carbon dioxide from combustion would continue to be vented to atmosphere or water and wasted.
The third option is one which has many advantages, has been little studied, and is the subject of this report. It consists of using the carbon dioxide as the basis for solid materials - plastics and other chemicals-which can serve as the basis for a 21 st century global industry and at the same time keep carbon dioxide out of the atmosphere.

Currently the world chemical industry, large as it is, uses a trivial amount of carbon compared with power-generating systems. Industry's use of waste carbon dioxide to make building materials will therefore neither deplete the supply nor drive up the raw material cost. Even in the 21st century, with decreased use of fossil fuel, this will remain true. Also in the 21st century, there will be 10 billion people who will represent a potential market for U.S.manufactured building products. Assume that at present each person in the United States has access to, use of, or control over from 1 to 1000 tons of material. This includes cars, homes, and a proportion of U.S. industrial infrastructure including production and transportation systems. Although this would be better stated on a volume basis-plastic is lighter than concrete-if each U.S. citizen in the 21 st century is responsible for the use of as much material as an average American of 1992, and if only $10 \%$ were based on carbon dioxide, the requirement for feedstock could be as large as 200 million (population) $\times 1000$ (tons) $\mathrm{x} 10 \%$, or 20 billion tons of carbon dioxide. Very little carbon dioxide-a negligible amount, in fact-is used as a chemical feedstock today; how is the changeover likely to be effected?

Plastics (synthetic polymers) other than natural rubber have only been a part of civilization during the 20th century, beginning with Bakelite (phenol-formaldehyde) and developing through BUNA-S synthetic rubber and polyethylene in the 1940 s to the ubiquitous plastics in use today, comprising millions of tons/year and 
thousands of compositions. World plastics production in 1981 was just 14 million mt, of which only 3 million $\mathrm{mt}$ was used as building materials (Dunlap and Desch 1982). In 1989, production of thermoplastics in Japan alone was 11.7 million mt (MPI 1990) and total world production including the major producers (the United States, Europe, Japan) was over 5 times this.

Hence, at a current use of plastics in building of $20 \%$ of total world production of 0.06 billion $\mathrm{mt}(=0.012$ billion $\mathrm{mt})$, replacement of this whole amount with polycarbonate-based materials produced from carbon dioxide at $50 \%$ by weight would currently require only 0.006 billion $\mathrm{mt}$ of carbon dioxide. To have any significant impact, at least a 100-fold increase in use of carbon-dioxide-based polymers is required in the next century (not allowing any decrement for recycling). The rate of increase over the last 10 years was approximately fivefold. Extrapolations based on this rate of increase indicate that the required 100 -fold increase could be achieved in 30 years without major societal changes being required. However, such extrapolations are notoriously inaccurate and can be relied upon only to within an order of magnitude. One definite conclusion is that it is technically feasible to accelerate production of carbon-dioxide-based plastic building materials to this level within 30 to 50 years.

In 1992, major plastics (other than those used for specialty applications such as laser disks, high-temperature applications, bearings, etc.) comprise polyvinyl chloride (PVC), polyethylene and polypropylene, nylons, polyurethanes, polystyrene, acrylonitrile-butadiene-styrene (ABS) copolymers, polyacrylates, polyterephthalates, and other polycarbonates. It may never be feasible to make a polycarbonate substitute for a synthetic rubber in a tire, for example, but it may be possible to make such a substitution for many of the uses of these plastics in the building industry. An example is the use of clear polycarbonate pipe to replace black $A B S$ in plumbing. 


\section{Carbon Dioxide Chemistry}

Carbon dioxide is the fully-oxidized form of carbon. To use it as a feedstock for most current chemical uses requires that it be reduced. This is what plants do in photosynthesis-reduce carbon dioxide to a onecarbon intermediate (for simplicity, consider this to be formaldehyde). This product is then used in synthesis of sugars and plant structural materials (cellulose, hemicellulose, and lignin).

In principle, carbon dioxide can replace oil and natural gas as a carbon basis for carbon monoxide production, but it must first be reduced:

$$
\mathrm{CO}_{2}+\mathrm{H}_{2}-\mathrm{CO}+\mathrm{H}_{2} \mathrm{O}
$$

This conversion requires energy, which must come from fossil fuel, nuclear power, or other energy source. Electricity can be used for the reduction (Erstfeld et al. 1979), but again, at a considerable cost in energy. If the energy source is the sun and the chemical factory is a green plant, the process is called photosynthesis:

$$
\mathrm{CO}_{2}+\mathrm{H}_{2} \mathrm{O} \rightarrow \mathrm{H} \cdot \mathrm{CH}=\mathrm{O}
$$

(Although formaldehyde is represented as the product, the product actually is a one-carbon unit that is incorporated into a 5-carbon sugar in the Calvin cycle.) A synthetic combination of the two approaches (photoelectrochemical conversion) has been demonstrated to convert carbon dioxide directly to gaseous and liquid fuel, but has an energy efficiency of only $4 \%$ at present (Mori et al. 1992). Fuel can also be produced directly from carbon dioxide and methane in a redox process based on the Fischer-Tropsch reaction, although energy efficiency was not considered (Fujimoto et al. 1992). These advanced processes are possible options for the future.
Based on the state of the art, a chemical industry that is based directly on the reduction of carbon dioxide would achieve nothing more than green plants do today, and at far higher cost in terms of money, equipment, and fuel; it would be better to change to an agriculturebased chemical industry, which is what will happen anyway when cheaper petroleum, coal, and natural gas supplies run out.

The chemical industry in the 20th century is very one-sided. It takes large resources of fully reduced fossil fuels and oxidizes them to intermediates; plants take fully oxidized carbon dioxide and reduce it to intermediates that are chemically very similar. The chemical industry does virtually no reduction of carbon dioxide, only oxidation of hydrocarbons. If the two processes could be coupled, chemical materials could be manufactured with very little net expenditure of energy and, hence, little need for fuel and power. This is illustrated in Figure 1.

Currently, several thousand organic chemicals are produced for use by industry: agricultural chemicals, plastics, paints, fibers, and so on. These in turn are produced from a limited number of organic chemical intermediates-the major industrial chemicals-including methanol, acetic acid, aromatics (benzene, toluene, xylenes), ethylene. In their turn, the heavy chemicals are produced from basic feedstocks (Table 1 illustrates this).

These "heavy chemicals" are petroleum and natural gas; almost no coal or biomass is used at the present time. Only aromatic chemicals and ethylene are made directly from petroleum. For the others, the major intermediates are carbon monoxide and hydrogen, generated by steam and air-reforming of petroleum hydrocarbons. Air-reforming is a partial oxidation. It 


\begin{tabular}{|c|c|c|c|}
\hline Feedstock & Process & Product & Energy Used \\
\hline \multirow[t]{2}{*}{$\mathrm{H}_{2} \mathrm{O}+\mathrm{CO}_{3}$} & Photosynthesis & $1 / 6 \mathrm{C}_{6}\left(\mathrm{H}_{2} \mathrm{O}\right)_{6}$ (Glucose) & +111.7 \\
\hline & Chemical Reduction & $\mathrm{CO}$ (Carbon monoxide) & +70 \\
\hline \multirow[t]{3}{*}{$\mathrm{CH}_{4}$} & Burn & & -213 \\
\hline & & $\mathrm{CO}_{2}$ & \\
\hline & Air reforming & $\mathrm{CO}$ & -143 \\
\hline $\begin{array}{l}\text { Photos } \\
\text { sum o } \\
\text { to cart }\end{array}$ & \multicolumn{3}{|c|}{$\begin{array}{l}\text { Photosynthesis requires additional energy to generate the relatively complex structure of glucose. The } \\
\text { sum of energies for the reforming of methane to carbon monoxide and oxidation of carbon monoxide } \\
\text { to carbon dioxide are equal. Energy values are in } \mathrm{Kcal} / \mathrm{g} \text {-atom of carbon. }\end{array}$} \\
\hline
\end{tabular}

Figure 1. Energetics of Methane Oxidation and Carbon Dioxide Reduction

Table 1. Source of Primary Chemicals in the United States in 1990 (Chemical Economics Handbook 1992)

\begin{tabular}{lclcc}
\multicolumn{1}{c}{ Source } & Percent & & Product & from Source \\
\cline { 4 - 5 } Natural Gas & 8.2 & Methanol & 95.3 \\
& & & \\
Natural Gas & 38.0 & Ethylene & 71 \\
Liquids and & & Propylene & 68 \\
Refinery Off- & & Butadiene & 48 \\
Gases & & Aromatics & Very small \\
& & & \\
Petroleum & 53.0 & Ethylene & 29 \\
& & Propylene & 32 \\
& & Butadiene & 52 \\
& & Benzene & 99.6 \\
& & Toluene & 99.6 \\
Coal & & Xylenes & 99.6 \\
& & & \\
& & & Methanol & 4.7 \\
& 0.8 & Benzene & 1.6 \\
& & Toluene & 0.4 \\
& & Xylenes & 0.4
\end{tabular}


is exothermic and is used to balance steam reforming, which is endothermic. An example of steam-reforming is the conversion of propane:

$$
\mathrm{C}_{3} \mathrm{H}_{2}+3 \mathrm{H}_{2} \mathrm{O}+3 \mathrm{CO}+7 \mathrm{H}_{2}
$$

The mixture of carbon monoxide and hydrogen made this way can be further converted to the correct mixture for making major chemicals such as methanol:

$$
\mathrm{CO}+2 \mathrm{H}_{2} \rightarrow \mathrm{CH}_{3} \mathrm{OH}
$$

Thus, with the exceptions noted above for aromatics and ethylene, the world organic chemical industry can be said to be based on carbon monoxide and hydrogen rather than natural gas and oil. Some hundreds of millions of tons of organic chemicals are made each year worldwide, if all chemicals are included and fuel uses are excluded.

Carbon monoxide and hydrogen can be made equally well from coal or biomass by wellestablished processes. Coal and biomass are not used, however, because the conversion methods incur additional cost and thus are currently not competitive. 


\section{Potential Uses for Carbon Dioxide in Polymers and Basic Chemicals}

Carbon dioxide used to make polymers requires no reduction and hence little or no additional energy. This use also ties the gas up in a solid, stable, recyclable and useful form. This approach makes use of the gas directly as a chemical intermediate for chemicals and particularly polymers and plastics.

\section{Carbon Dioxide as a Chemical Feedstock}

Carbon dioxide can be regarded as a diketone of low chemical activity:

\section{$H \cdot C H=O$ (Formaldehyde);}

$\mathrm{O}=\mathrm{C}=\mathrm{O}$ (Carbon diaxide); $\left(\mathrm{CH}_{3}\right)_{2} \mathrm{C}=\mathrm{O}$ (Acetone)

As such, it takes part in reactions involving typical ketone functions of reduction, addition, and condensation (it cannot be oxidized).

\section{Polymers}

Addition and condensation reactions are the key to the use of carbon dioxide as a polymer feedstock, since reduction would be too inefficient in energy for use on a large scale.

Two particular reactions, one an addition and the sther a condensation, will be used for making carbon dioxide-based polymers. These are the reactions with alkylene oxides (oxetanes) and amines to generate polycarbonates and polyureas, respectively:

$$
\begin{gathered}
\left.\mathrm{CO}_{2}+\mathrm{CH}_{3} \cdot \mathrm{CH}^{\prime} \mathrm{O}\right) \cdot \mathrm{CH}_{2}-\left[\mathrm{OH}_{3} \cdot \mathrm{CH}_{2}-\mathrm{CH}_{2} \cdot \mathrm{O} \cdot \mathrm{CO} \cdot \mathrm{O}\right]_{n} \\
\text { (polycarbonates) }
\end{gathered}
$$

$$
\begin{gathered}
\mathrm{CO}_{2}+\mathrm{H}_{2} \mathrm{Naalkyl} \cdot \mathrm{NH}_{2}-[-\mathrm{NH}-\mathrm{CO}-\mathrm{NH} \text { alkyl. } \mathrm{NH}-\mathrm{CO}-] \\
\text { (polyureas) }
\end{gathered}
$$

These are not the only representatives of their classes. Polycarbonates include a large variety of polymer structures with different alkyl or aryl groups and are widely used in various industries. Polyamides include polyureas, nylons, melamines (urea-formaldehydes), and various other structures.

Literally thousands of usuful structural polymer materials can be made by these two basic reactions. In principle at least, carbon-dioxide-based polymers can be developed for any use currently met with pure organic polymers. (Further discussion of the uses for these materials is presented in the next section). Using carbon dioxide in this way not only takes it out of atmospheric circulation, it also "stretches" our available petroleum resources by adding units of molecular weight 44 to every pure organic monomer feedstock molecule.

\section{Agricultural Chemicals}

Carbon dioxide is used in the manufacture of urea, a major agricultural fertilizer, and as a starting point for urea-based plastics. Carbon dioxide is reacted with ammonia to form ammonium carbamate, which, upon heating, eliminates water to form urea.

Carbon dioxide can be used to make phosgene (carbonyl chloride) by reaction with carbon and chlorine, in a reduction/addition reaction:

$$
\mathrm{CO}_{2}+\mathrm{C}+2 \mathrm{Cl}_{2}-2 \mathrm{COCl}_{2}
$$


Currently, phosgene is made from carbon monoxide in an exothermic reaction. Phosgene is an intermediate in the production of carbamate herbicides via methyl isocyanate.

\section{Other Chemicals}

Electrolytic reduction and coupling of two molecules of carbon dioxide yield oxalic acid, which is a useful starting point for a variety of oxalate-based chemicals, including plasticizers and esters. Further reduction of carbon dioxide in an electrolytic cell has been shown to produce carbon monoxide (Erstfeld et al. 1979). This carbon monoxide can, in turn, be used in the manufacture of thousands of chemicals, including the bulk chemicals methanol and acetic acid.

\section{Properties and Uses of Carbon- Dioxide-Based Polymers}

The utility of polymers containing carbon dioxide in chemically bound form is shown in the following examples.

\section{Polyalkylene Carbonates}

Arco Corporation and Air Products and Chemical Corporation are jointly developing polyalkylene carbonate plastics for use in coatings, adhesives, and packagings (Chemical Engineering 1986). The following is quoted from this reference: "The polymers may be competitive with commercial packaging materials and adhesives since they contain 50\% carbon dioxide by weight. The polymers burn cleanly in aic and thermally decompose at 200 250 degrees Celsius, making them ecologically attractive.... A new clear, recyclable film can be used as an oxygen barrier. It is resistant to abrasion, stains, gasoline and oil and has an excellent adhesion to wood and paper." These polycarbonates have been made with molecular weights averaging 200,000 and a tensile strength of 1000 psi (Santangelo et al. 1987).

\section{(Poly)Aryl Carbonates}

Replacement of a linear alkylene group with an aromatic group in the polycarbonate molecule yields plastics with different properties. If bisphenol $\mathrm{A}$ is used instead of propylene oxide, an amorphous thermo-plastic is obtained (EMD 1985). These thermoplastics can be combined with up to $40 \%$ glass to yield a transparent, chemical resistant, flame-retardant polymer which can be used in making compact discs. (Bisphenol A can be made from phenol derived from coal, oil, or biomass).

The carbon dioxide content of these polymers can be increased to about $70-80 \%$ by direct microbubble injection of carbon dioxide, (Schnell 1990). Work done at the University of Washington is reported to yield a microcellular polycarbonate plastic without loss of strength, with a $40 \%$ reduction in material density (Kumar et al. 1990). The carbon-dioxideinjected plastics are lightweight, tough, and suitable for a wide range of applications ranging from aircraft and automobiles to toys. Density reductions of up to $90 \%$ are achievable with some loss of rigidity. This density plastic could be used as building insulation with the inherent advaritage of containing its own fire-extinguishing gas. The denser material could be used for making building panels.

\section{Polyureas}

Polyurea research is less well advanced than polycarbonate research; nevertheless, carbondioxide-based polyureas of high molecular weights have been made, using oxydianiline as the organic monomer (Higashi et al. 1982; Rokicki 1988). 


\section{Polyurethanes}

These polymers usually comprise a condensation product of a glycol and a diisocyanate and are intermediate in chemical structure between a polycarbonate and a polyuria; they find wide applications in insulation and foams:

$$
\begin{gathered}
H O-R-O H+O C N \cdot R^{\prime} \cdot N C O \\
{\left[-O R-O-C=O \cdot N H \cdot R^{\prime} \cdot N H \cdot C=O \cdot-\right]_{k}}
\end{gathered}
$$

Polyurethanes can also be made by the reaction between carbon dioxide and an imine or an aziridine, for example propyleneimine (Soga et al. 1974).

\section{Aramids}

Aramids are a class of aromatic amide polymers which have exceptional thermal stability and are being developed for use in high-temperature applications (up to $400^{\circ} \mathrm{C}$ ). To date, carbon monoxide has been used as the linking agent in work by a Japanese group (Yoneyama et al. 1988). This application is given here because of its potential importance. The synthesis involves the carbonylation polymerization of aromatic dibromides and aromatic diamines with carbon monoxide in the presence of a palladium catalyst.

\section{Other Polymers}

Carbon dioxide has been used to prepare polymer types other than the major ones listed above. These include polyethers, polyketones, and silicones. Also, many of the most important industrial polymers are copolymers of several monomers or are composites. Two examples of such bulk industrial polymers are ABS (acrylonitrile-butadiene-styrene) used in making black plastic pipe mostly for plumbing uses and various synthetic rubbers (nitrile-butadiene, styrene-butadiene, etc.) These are virtually all petroleum-based hydrocarbon (reduced) polymers and offer little prospect for replacement by carbon dioxide polymers in the near future, although little work has been done to investigate this concept. 


\section{Conclusions}

This study was undertaken to determine the possibility of using carbon dioxide rather than burying it in the oceans or the atmosphere. Silica (poly-silicon dioxide) is used worldwide in building as a basic, major component of building materials from concrete to mud. Could carbon dioxide, which does not form a polymer by itself, be used with other chemicals to make a lightweight, strong, and not too expensive alternative to silica-based structures? If so, the carbon dioxide would be fixed in a solid, useful form where it would contribute to industrial development. A preliminary examination of this concept led to the following general conclusions:

1. Use of carbon dioxide as a chemical feedstock is technically feasible, although it may be very expensive in terms of energy use because the carbon dioxide must first be partially reduced.

2. Conclusion 1 is not true for carbon-dioxidebased polymers, which do not require reduction of carbon dioxide, but instead are made by direct copolymerization with amines or epoxides. The resulting polymer has up to $50 \%$ by weight carbon dioxide content.
3. Polycarbonates containing up to $90 \%$ by weight of carbon dioxide have been made by gas microbubble impregnation technology. Polycarbonates are strong enough to be used in building and manufacturing.

4. A 100-to 1000-fold increase in the use of carbon-dioxide-based plastics in the next century could result in a very significant benefit to industry, which is faced with shortages of wood and high-energy costs to produce concrete and metals.

5. The organic co-monomers which are reacted with carbon dioxide to form the copolymers can themselves be made directly or indirectly from biomass rather than from fossil fuels.

6. Specific cost data on carbon-dioxide-based polyme-s were not located in this study, but general references to their being of "low cost" were found.

7. Based on the results of this preliminary study, a more in-depth study would be justified to develop a strategy for achieving greater use of carbon-dioxide-based polymers. 


\section{References}

Barfield, B. J., J. F. Clarke, O. J. Loewer, and M. Collins. 1991. "Identification and Assessment of Critical Issues Relative to Modeling Biomass Energy Production - A Response to Potential Climate Change." Proceedings: Global Biomass Workshop, Lexington, Kentucky, September 9-11, 1991. Pacific Northwest Laboratory, Richland, Washington, and University of Kentucky, Lexington, Kentucky.

Burton, J. 1992. "Carbon Dioxide Emissions." Chem. Eng. News, 70, 2.

Chemical Economics Handbook. 1992. SRI International, Menlo Park, California.

Chemical Engineering. November 24, 1986.

"ARCO and Air Products Join Forces to Develop New Low-Cost Polymer," pp. 11.

Clarke, J. F. 1991. "Biomass in a Global Context - Consequences of a Policy Response to Global Climate Change." Proceedings: Global Biomass Workshop, Lexington, Kentucky, September 9-11, 1991. Pacific Northwest Laboratory, Richland, Washington, and University of Kentucky, Lexington, Kentucky.

Dunlap, L. H., and R. Desch. 1982. "Plastic Building Products." Kirk-Othmer Encyclopedia of Chemical Technology 18, 108. John Wiley \& Sons, New York.

Engineering Materials \& Design (EMD). February 1985. "Polycarbonate: A Unique Spectrum of Properties," 29 (2):38, 41.
Erstfeld, T. E., O. Mullins, Jr., and R. J. Williams. 1979. "Carbon Dioxide Electrolysis Using a Ceramic Electrolyte." Space Manufacturing III, J. Grey and C. Kopp, eds., pp. 83-88. Proceedings of the Fourth Princeton/AIAA Conference, Princeton, New Jersey, May 14-17, 1979. American Institute of Aeronautics and Astronautics, New York.

Fujimoto, K., K. Omate, T. Nozaki, O. Yamazaki, and Y. Hah. 1992. "Selective Synthesis of Liquid Hydrocarbons from Carbon Dioxide and Methane." Proceedings of the First International Conference on Carbon Dioxide Removal, K. Blok, W. C. Turkenburg, C. Hendriks, and M. Steinberg, eds. Amsterdam, The Netherlands, March 4-6, 1992. Energy Conversion and Management, Special issue, Vol. 33, No. 5-8.

Higashi, F., T. Murakami, and Y. Taguchi. 1982. "Polyureas from Carbon Dioxide and Diamines by Means of Triphenyl Phosphite and Pyridine Hydrochloride." J. Polymer Sci., Polymer Chem. Ed. 20, 103-108.

Hileman, B. 1992. "Web of Interactions Makes It Difficult to Untangle Global Warming Data." Chem. Eng. News 70, 7-19.

Kumar, V., J. Weller, and H. Y. Hoffer. 1990. "Synthesis of Microcellular Polycarbonate: A Phenomenological Study of Bubble Nucleation and Growth." Proceedings of the Symposium on Processing Polymers and Polymeric Composites, MD-19: 197-212. Winter Annual Meeting, Dallas, Texas, November 26, 1990. American Society of Mechanical Engineers, New York. 
Madern Plastics International (MPI), p. 142. October 1990.

Mori, T., R. Doi, H. Tobita, and H. Miyadera. 1992. "Photoelectrochemical Conversion of Carbon Dioxide to Fuels." Proceedings of the First International Conference on Carbon Dioxide Removal, K. Blok, W. C. Turkenburg, C. Hendriks, and M. Steinberg, eds. Amsterdam, The Netherlands, March 4-6, 1992. Energy Conversion and Management, Special issue, Vol. 33, No. 5-8.

Owen, G. December 1991. "Climate Change CHP's Role in Reducing $\mathrm{CO}_{2}$ Emissions." Pollution Prevention, pp. 11-14.

Pitelka, L. January/February 1992. "Forest Response to Carbon Dioxite." EPRI Journal, pp. 38-41.
Rokicki, G. 1988. "Direct Method of Synthesis of Polyureas by N-Acylphosphoramidites." Makromol. Chem., 189, 2513-2520.

Santangelo, J. G., J. J. Weber, and R. G. Sinclair. 1987. "Alkylene Carbonate Block Polymers." U.S. Patent 4,665,136.

Soga, K., W.-Y. Chiang, and S. Ikeda. 1974. "Copolymerization of Carbon Dioxide with Propyleneimine." J. Polymer Sci., Polymer Chem. Ed., 12, 121-131.

Yoneyama, M., M. Kakimoto, and Y. Mimai. 1988. "Novel Synthesis of Aromatic Polyamides by Palladium-Catalyzed Polycondensation of Aromatic Dibromides, Aromatic Diamines, and Carbon Monoxide." Macromolecules, 21, 1908-1911. 


\section{Bibliography}

\section{Polyuria}

Chiriac, C. 1., Polymer Bull. (Berlin), 15, 6568 (1986). "Aromatic Polyureas and Polythioureas by a New Polycondensation Reaction Using Ethylene Chlorophosphite as Reagent."

Ethylene chlorophosphite used as catalyst in pyridine for the direct condensation of aromatic diamines with $\mathrm{CO}_{2}$.

Higashi, F., T. Murakami, and Y. Taguchi, $J$. Polymer Sci., Polymer Chem. 20, 103-108 (1982). "Polyureas from Carbon Dioxide and Diamines by Means of Triphenyl Phosphite and Pyridine Hydrochloride."

The reaction occurred with diamines, such as ODA and MDA, in presence of 40-50 atm $\mathrm{CO}_{2}$ and $60-80^{\circ} \mathrm{C}$ with $\mathrm{N}$-methylpyrrolidone solvent for $5 \mathrm{~h}$ with varying amounts of triphenyl phosphite and pyridine $\mathrm{Hcl}$, usually stoichiometric, to give high MW polyuria.

Rokicki, G., Makromol. Chem., 189, 25132520 (1988). "Direct Method of Synthesis of Polyureas by $\mathrm{N}$-acylphosphoramidites."

Diethylphosphorchloridite reacted with methylacetamide to form the catalyst for polymerization of $\mathrm{CO}_{2}$ with diamines such as oxydianiline. This provides mild conditions for the polymerization.

\section{Polycarbonate}

Aida, T., M. Ishikawa, and S. Inoue, Macromolecules, 19, 8-13 (1986). "Alternating Copolymerization of Carbon Dioxide and Epoxide Catalyzed by the Aluminum PorphyrinQuaternary Organic Salt or Triphenylphosphine System. Synthesis of Polycarbonate with WellControlled Molecular Weight."
Aliphatic carbonate prepared with a narrow molecular weight distribution. Quat ammonium or phosphonium salt used as satalyst with the Al porphyrin.

Andreozzi, R., M. C. Annesini, M. Chiarotti, and F. Pochetti, Chim. Ind. (Milan), 67, 481483 (1985). "Synthesis of Alkylene Carbonates with Alkaline Halides Supported on Active Carbon."

$\mathrm{KI}$ was best catalyst for propylene oxide (PO)$\mathrm{CO}_{2}$ copolymerization. Reaction done at $\mathrm{CO}_{2}$ pressure and various temperatures.

Baba, A., H. Kashiwagi, and H. Matsuda, Tetrahedron Lett., 26, 1323-1324 (1985).

"Cycloaddition of Oxetane and Carbon Dioxide Catalyzed by Tetraphenylstilbunium Iodide"

Trimethylene carbonate was obtained in this reaction.

Baba, A., H. Kashiwagi, and H. Matsuda, Organometallics, 6, 137-140 (1987). "Reaction of Carbon Dioxide with Oxetane Catalyzed by Organotin Halide Complexes: Control of Reaction by Ligands"

Butyltin halides used as catalyst for this copolymerization.

Baba, A., H. Meishou, and H. Matsuda, Makromol. Chem., Rapid Commun., 5, 665-668 (1984). "Copolymerization of Oxetane with Carbon Dioxide with Organotin Halide/Lewis Base Systems"

Mixtures of alkyltin halides and tert. phosphines or amines had high catalytic activity for making carbonates with oxetane and $\mathrm{CO}_{2}$ with an MW of 1000-1400. 
Baughman, R. H., Z. Iqbal, and H. Eckhardt, Macromolecules, 21, 1832-1838 (1988).

"Structure, Properties and Thermodynamics of Poly(carbon dichalcogenides)"

Calculations were used to model compounds based on poly (carbon dioxide). The heat and free energy of polymerization were based on the models.

Bullen, R. S., J. Mzik, and J. P. Richard, U.S. Patent 4,701,270 (1987) to Canadian Fracmaster Ltd. "Novel Composition Suitable for Treating Deepwells"

A copolymer of $\mathrm{PO} / \mathrm{CO}_{2}$ was made with zinc acetate and acetic anhydride as catalyst. The polymer was used with liquid carbon dioxide as a thickener for fracturing fluid.

Cannarsa, M. J., H. S. Kesling, and D. E. Hostetler, U.S. Patent 4,833,036 (1989) to Arco Chemical Technology Inc. "Poly(alkylene carbonate)-Rubber Blend Hot-Melt Adhesives"

$\mathrm{CO}_{2}$-cyclohexene oxide-PO copolymer was mixed with SBR and a propylene carbonate plasticizer to give excellent results for the adherence of metals and dissimilar polymers.

Chen, L. I., H. S. Chen, and J. Lin, Macromol. Sci., Chem., A24, 253-260 (1987). "Copolymerization of Carbon Dioxide and Propylene Oxide with Zinc Catalysts Supported on Carboxyl-Containing Polymers"

Diethylzinc was reacted with polymers containing carboxyl groups; styrene-acrylic acid was better than polyacrylic acid alone. The yields of the polymer increased with increased reaction time.

Chen, L., H. Peng, X. Lin, and H. Chen, Faming Zhuanli Shenging Gonkai Shuomingshu CN 1,044,663 (1990). Chem. Abstr. 116:60193p. "Catalysts for Synthesizing Polycarbonates, Polyesters, and Polyethers"
$\mathrm{PO} / \mathrm{CO}_{2}$ copolymers prepared with $\mathrm{ZnCl}{ }_{2}$ $\mathrm{K}_{3} \mathrm{Fe}(\mathrm{CN})_{6}$ - glycerol - dimethylether to give carbonate with an average molecular weight of 10,000 .

Chen, L., H. Lin, H. Chen, and J. Lin, Yingyong Huaxue, 5, 7-11 (1988). "ZincAluminum Bimetallic Catalysts for the Copolymerization of Carbon Dioxide with Propylene Oxide"

$\mathrm{Zn}$ salt was reacted with triethylaluminum and a proton-containing compound as catalyst. $\mathrm{A}$ carboxyl-containing compound was used as cocatalyst.

Chen, X. S., and Z. Y. Zhiquan, Macromolecules, 24, 5305-5308 (1991). "New Catalytic Systems for the Fixation of Carbon Dioxide. 1. Copolymerization of Carbon Dioxide and Propylene Oxide with New RareEarth Catalysts."

Rare earth phosphate esters with $\mathrm{i}-\mathrm{Bu}_{3} \mathrm{Al}$ were used as catalysts for $\mathrm{PO} / \mathrm{CO}_{2}$ copolymerization.

Frechet, J.M.J., F. M. Houlihan, and C. G. Wilson, Polym. Mater. Sci. Eng., 53, 268-272 (1985). "Polycarbonates Derived from 0Nitrobenzyl Glycidyl Ether; Synthesis and Radiation Sensitivity"

Diethylzinc-pyrogallol catalyzed system used for $\mathrm{PO}-\mathrm{CO}_{2}$ with the nitro-compound inclusion. The nitrobenzyl group was removed with uv with no main-chain cleavage. This polycarbonate, as hydroxymethylated, was stable for $>1 \mathrm{yr}$ and was heat stable to $200^{\circ} \mathrm{C}$, but it would undergo acid catalyzed decomposition.

Hostetler, D. E., M. J. Cannarsa, and H. S. Kesling, U.S. Patent 4,853,462 (1989) to Arco Chemical Technology Inc. "Precipitation of Polyalkylene Carbonate Microspheres from Solution" 
Cyclohexene oxide with $\mathrm{PO}$ and $\mathrm{CO}_{2}$ was copolymerized in propylene glycol acetate and cooled rapidly to give $160-600$ micron particles useful for foam molding.

Inoue, S., NATO ASI Ser., Ser. C, 206, 331337 (1987). "Copolymerization of Carbon Dioxide and Epoxide"

A review of the copolymerization techniques, particularly stressing catalysts types. Also, information discussing the mechanisms is presented.

Inoue, S., Prog. Polym. Sci., Japan, 8, 1-42 (1975). "Copolymerization of Carbon Dioxide"

An excellent review of synthetic procedures with a variety of monomers for the preparation of polycarbonates from $\mathrm{CO}_{2}$ and epoxides. Considerable coverage is given for the catalysts, particularly diethylzinc. Stereochemistry and mechanisms are also covered. The reaction with aziridines and diamines is also discussed.

Inoue, S., Fundam. Res. Semin. Organomet. Chem., Proc. China-Jpn-U.S. Trilateral Semin. Organomet. Chem. 1st 1980 (Pub. 1982), 125148, Editors; M. Tsutsui, Y. Ishii, and $Y$ Huang; Van Nostrand Reinhold, New York. Chem. Abstr. 97:72787n. "Organometallic Catalysts in Carbon Dioxide Fixation"

Discusses polycarbonate formation from carbon dioxide and reviews the various catalysts with activity/structure relationships. The effect of visible light on reactivity is also included.

Inoue, S., T. Aida, and K. Shimazaki, Jpn. Kokai Tokyo Koho JP 02,132,123 (1990) to Tokuyama Soda Co. "Poly(epiclorohydrin carbonates) with Narrow Molecular Weight Distribution" Chem. Abstr. 113:212902x
Epichlorohydrin and $\mathrm{CO}_{2}$ were polymerized with an Al tetrabenzoporphyrin catalyst to give $86 \%$ yield and an $\mathrm{MW}$ of 5000 .

Kawachi, H., S. Minami, J. N. Armor, A. Rokicki, and B. K. Stein, Eur. Pat Appl. EP 358326 A1 to Mitsui Petrochemical Industries, Ltd. "Zinc-Containing Solid Catalyst, Process of Preparing Same and Process for Preparing Polyalkylene Carbonate"

Organic dicarboxylic acids reacted with zinc oxide for use as a catalyst for the polymerization of carbon dioxide and propylene oxide.

Kesling, H. S., M. J. Cannarsa, and H. N. Sun, U.S. Patent 4,851, 507 (1989) to Arco Chemical Technology Inc. "Melt-Processable Aliphatic Polycarbonate Terpolymers"

Cyclohexene oxide, $\mathrm{PO}$, and $\mathrm{CO}_{2}$ copolymer was prepared with a glass transition temperature of $38^{\circ}$ and a decomposition temperature of $246-261^{\circ} \mathrm{C}$.

Kobayashi, M., Y.-L. Tang, T. Tsuruta, and S. Inoue, Makromol. Chem., 169, 69-81 (1973). "Copolymerization of Carbon Dioxide and Epoxide Using Dialkyl/Dihydric Phenol System as Catalyst"

Description of the $\mathrm{PO}-\mathrm{CO}_{2}$ polymerization with diethylzinc/phenol catalyst. Considerable discussion is presented of the catalyst mechanism and its incorporation into the polymer structure.

Kudashev, R. K., E. A. Glukhov, E. A. Kuramshina, and Y. B. Monakov, Dokl. Akad. Nauk SSSR, 292, 894-897 (1987). "Copolymerization of Glycidyl Ethers with Carbon Dioxide on a Homogeneous Catalyst"

Relative reactivity of glycidyl ethers increased in order of $\mathrm{R}$ : allyl $<\mathrm{Bu}<\mathrm{Ph}<\mathrm{p}$-cresyl. The catalyst was iso- $\mathrm{Bu}_{3} \mathrm{Al}-\mathrm{H}_{2} \mathrm{O}$-epichlorohydrin. 
Kuran, W., Appl. Organomet. Chem., 5, 191-4 (1991). "Active Sites, Nature, and Mechanism of Carbon Dioxide-Propylene Oxide Copolymerization and Cyclization Reactions Employing Organozinc-Oxygen Catalysts"

Author used diethylzinc-phenol catalyst as part of a mechanism study for this copolymerization.

Kuran, W., and A. Rokicki, Angew. Makromol. Chem., 78, 217-220 (1979). "Properties of $\mathrm{CO}_{2}$ Copolymers with Heterocyclic Monomers"

Properties of $\mathrm{PO}-\mathrm{CO}_{2}$ and methylaziridine$\mathrm{CO}_{2}$ polymers were estimated as well as those of styrene oxide and commercial 4,4'isopropylidenediphenylcarbonate.

Kuran, W., and P. Gorecki, Pol. PL 120,673 (1983) to Politechnika Waszawska. "High Molecular Weight Aliphatic Polycarbonates"

Copolymers of an epoxy (PO) and carbon dioxide were prepared with a diethylzinc/4bromopyrogallol catalyst in dioxane under $60,000 \mathrm{hPa} \mathrm{CO}$ and heated to $35^{\circ}$ for $70 \mathrm{~h}$.

Kuyper, J., P. W. Lednor, and G. A. Pogony, Eur. Pat. Appl. EP 222,453 (1987). "Process for the Preparation of Polycarbonates"

$\mathrm{CO}_{2}$-epoxides copolymerized at $40-200^{\circ} \mathrm{C}$ and 2-40 bar with a catalyst of $\mathrm{Zn}_{3}\left[\mathrm{Co}(\mathrm{CN})_{6}\right]_{2}$ $\mathrm{ZnCl}_{2}-\mathrm{ZnSO}^{4}$.

Lednor, P. W., and N. C. Rol, J. Chem. Soc., Chem. Commun., 589-599 (1985). "Copolymerization of Propylene Oxide with Carbon Dioxide; A Selective Incorporation of Propylene Carbonate into the Polycarbonate Chains, Determined by $100 \mathrm{Mhz}$ carbon-13 NMR"

Diethylzinc was used as catalyst for the polymerization at $23-55^{\circ} \mathrm{C}$ in dioxane-water. They report significant amounts of inverted
PO units in the polymer. This is contrary to work by Rokicki and Kuran of 1981 .

Markevich, M. A., L. I. Pavlinov, and Y. A. Lebedev, Dokl. Akad. Nauk SSSR, 226, 652655 (1982). "Thermodynamics of the Addition of Carbon Dioxide to Vinyl Monomers,

Aldehydes, and Epoxy Compounds"

Enthalpies, entropies, and free energies were calculated for PO and carbon dioxide polymerization.

Meyers, M. O. Eur. Pat. Appl. EP 228,037 (1987). "Process for Preparing Poly(alkylene carbonates)"

$\mathrm{CO}_{2}$-epoxides made in presence of $\mathrm{NaSnO}_{3}$ and potassium carbonate at $175^{\circ} \mathrm{C} / 400 \mathrm{psi}$ with EO and time of $13 \mathrm{~h}$.

Motika, S. A., T. L. Pickering, A. Rokicki, and B. K. Stein, U.S. Patent 5,026,676 (1991) to Air Products and Chemicals, Inc. "Catalyst for the Copolymerization of Epoxides with $\mathrm{CO}_{2}{ }^{n}$

The patent describes zinc carboxylate (adipate, glutarate) as a catalyst for propylene oxide with carbon dioxide or carbon monoxide copolymers.

Nakayama, M., T. Kuwabara, and K. Ueda, Jpn. Kokai Tokyo Koho JP 63,251,950 to TDK Corp. "Optical Recording Medium with Film Prepared by Plasma Polymerization" Chem. Abstr. 110:222726v

Plasma polymerization mix contained $\mathrm{CO}_{2}$ and methane to form the polycarbonate as a film for the recording medium.

Nanao, T., and S. Inoue, Jpn. Kokai Tokyo Koho JP 62,246,856 (1987) to Kanegafuchi Chemical Industry Co. Ltd. "Aliphatic Polycarbonate Binders for Sintering of Ceramics" 
$\mathrm{PO} / \mathrm{CO}_{2}$ copolymer with a molecular weight of 100,000 was mixed with Ba titanate and sintered at $800^{\circ} \mathrm{C}$ to give a ceramic free of carbon.

Ninagawa, A., T. Suzuki, and H. Matsuda, Chem. Express, 1, 169-172 (1986). Japanese; Chem. Abstr. 106:50089p. "Effect of Ultrasound on the Reaction of Carbon Dioxide with Epoxides Catalyzed by Organotin and Antimony Halides"

Ultrasound accelerates the reaction of butylene oxide and carbon dioxide.

Rokicki, A., U.S. Patent 4,943,677 (1989) to Arco Chemical Co. and Misui Petrochemical Industries, Ltd. "Poly(alkylene carbonates) with Controlled Molecular Weight"

$\mathrm{Zn}$ glutarate catalyst used for $\mathrm{PO} / \mathrm{CO}_{2}$ to give a polymer of 100,000 molecular weight.

Rokicki, G. and P. Jezewski, Polymer J. (Tokyo), 20, 499-509 (1988). "Polycarbonates from Cyclic Carbonates, Carbanions, and Dihalo Compounds"

Block polymerization was attained with styrene and ethylene carbonate as well as cyclic carbonates with potassium naphthalene and dihalo compounds such as dibromoxylene. In particular, 1,3-dioxolan-2-one ring openings were discussed for the mechanism of carbonate linkage. When oxiranes and $\mathrm{CO}_{2}$ were used instead of cyclic carbonates, a product containing built-in polyether segments in various lengths was formed.

Rokicki, G., W. Witold, and J. Kielkiewicz, J. Polymer Sci., Polym. Chem. Ed., 20, 967-976 (1982). "Synthesis of a Polycarbonate by Reaction of Carbon Dioxide, Potassium 4,4'Isopropylidenediphenolate and $\alpha, w$-Dihalo Compounds"
Crown ethers were used as catalysts in polar, aprotic solvents for polymerization of the title components.

Rokicki, A. and W. Kuran, J. Macromol. Sci., Rev. Macromol. Chem., C21, 135-185 (1981). "The Application of Carbon Dioxide as a Direct Material for Polymer Syntheses in Polymerization and Polycondensation Reactions"

An updated review of the polycarbonate (especially) and polyurethane preparation with the use of carbon dioxide. 91 references.

Santangelo, J. G., J. J. Weber, and R. G. Sinclair, U.S. Patent 4,665,136 (1987) to Air Products and Chemicals Inc. "Alkylene Carbonate Block Polymers"

The reaction was performed with dioxane, Diethylzinc, $\mathrm{Al}_{2}\left(\mathrm{SO}_{4}\right)_{3}$ with carbon dioxide and propoylene oxide for $52 \mathrm{~h}$ at $122^{\circ} \mathrm{F}$; then ethylene oxide was added and mixture stirred for $4 \mathrm{~h}$ to give a clear, tough polymer with an average molecular weight of 200,000 . The glass transition temp was $27^{\circ} \mathrm{C}$ and tensile strength was $1000 \mathrm{psi}$. Polymer soluble in dichloromethane and chloroform.

Shimazaki, K., Y. Mizutani, and H. Takeuchi, Jpn Kokai Tokyo Koho JP 02,142,824 (1990). "Copolymers of Alkylene Oxide, Epichlorohydrin, and Carbon Dioxide and Manufacture" Chem. Abstr. 113:192188p

The catalyst was Al porphyrin for PO, epichlorohydrin, $\mathrm{CO}_{2}$ polymerization conducted at $25^{\circ}$ for $101 \mathrm{~h}$ and $50 \mathrm{Kg} / \mathrm{cm}^{2}$ to give 50,000 molecular weight.

Soga, K., K. Hyakkoku, and S. Ikeda, J. Polymer Sci., Polymer Chem. Ed., 17, 2173-2180 (1979). "Copolymerization of Carbon Dioxide and Propylene Oxide with Supported Diethylzinc Catalysts" 
Diethylzinc was supported on various metal oxides such as $\mathrm{SiO}_{2}, \mathrm{MgO}$, and $\mathrm{Al}_{2} \mathrm{O}_{3}$ and used as the catalyst for the reaction $\mathrm{CO}_{2}$ and propene. Reaction done in stainless steel reactor with dioxane for $15 \mathrm{~h}$ at $60^{\circ} \mathrm{C}$. Pressure not designated. The product is an alternating copolymer.

Sugiyama, K., K. Shiraishi, T. Ihara, and M. Kiboku, Polymer J., 23, 1287-1290 (1991). "Thin Films Plasma Polymerized from Propylene Oxide and Carbon Dioxide Mixture"

$\mathrm{PO}$ and $\mathrm{CC}_{2}$ were polymerized in a plasma reactor with no catalyst to form thin film deposits. Analysis confirms $\mathrm{CO}_{2}$ incorporation in the polymer.

Sun, H. N., U.S. Patent $4,783,445$ (1988) to Arco Chemical Co. "Soluble Catalysts for Polymerization of Epoxides with Carbon Dioxide"

Zinc compounds with dicarboxylic acids and anhydrides (maleic) were used as soluble catalysts for the polymerization of carbon dioxide with epoxides such as cyclohexene oxide.

Sun, H. N., U.S. Patent 4,789,727 (1988) to Arco Chemical Co. "Enhancement of Catalyst Activity in Epoxide-Carbon Dioxide Copolymerization"

$\mathrm{Zn}$ carboxylate catalysts enhances the reaction if a small amount of diepoxide is added, for instance, dicyclopentadiene dioxide. This gives a yield of $65 \%$ for $\mathrm{PO} / \mathrm{CO}_{2}$ copolymer.

Takanashi, M., Y. Nomura, Y. Yoshida, and S. Inoue, Makromol. Chem., 183, 2085-2092 (1982). "Functional Polycarbonate by Copolymerization of Carbon Dioxide and Epoxide: Synthesis and Hydrolysis"

Catalyst used was diethylzinc-water. Polycarbonates undergo acid and base hydrolysis to release the component attached as the pendant group via the carbonate linkage Other hydrolysis products were glycerol and carbon dioxide, but no oligomers were formed.

Yoshida, Y., A. Nishiyama, and S. Inoue, Polymer J. (Tokyo), 14, 327-330 (1982).

"Synthesis and Reactions of Polycarbonates with Pendant Vinyl Groups"

Title compounds formed with butadiene monoxide, carbon dioxide, and optinnally, PO, with diethylzinc-water catalyst. They performed reaction by brominating, treatment with KOAc, followed by Pt-organocomplex to yield pendant vinyl. The vinyl is complexed with the Pt and gives slow release of that metal.

\section{Polyurethane}

Kuran, W., A. Rokicki, and D. Romanowska, J. Polymer Sci., Polymer Chem. Ed., 17, 20032011 (1979). "A New Route for Synthesis of Oligomeric Polyurethanes. Alternating Copolymerization of Carbon Dioxide and Aziridines"

2-Me and 1-phenethylaziridine were polymerized with $\mathrm{CO}_{2}$ in presence of organozinc catalyst. 60 atm of $\mathrm{CO}_{2}$ with sub-EI for $44 \mathrm{~h}$ and $35^{\circ} \mathrm{C}$ for low MW products. Mechanism proposed.

Soga, K., W.-Y. Chiang, and S. Ikeda, J. Polymer Sci., Polymer Chem. Ed., 12, 121-131 (1974). "Copolymerization of Carbon Dioxide with Propyleneimine"

EI and $\mathrm{CO}_{2}$ were polymerized in an SS autoclave up to $100^{\circ} \mathrm{C}$ for $93.9 \%$ conversion. Mechanism is proposed.

Soga, K., S. Hososa, and S. Ikeda, Makromol. Chem., 175, 3309-3313 (1974). "Copolymerization of Carbon Dioxide and Ethylenimine" 
$\mathrm{EI}$ and carbon dioxide polymerized at $80^{\circ}$ without solvent or catalysts to give linear polyurethanes.

Soga, K., S. Hososdla, and S. Ikeda, J. Polymer Sci., Polymer Chem. Ed., 12, 729-736 (1974). "Copolymerization of Carbon Dioxide and NPhenylethylenimine"

The polymerization catalyst for the title reaction was manganese bis(acetylacetonate) and several other related organometallics in hexane. Yield increased with carbon dioxide concentration in feed and polymerization temperature.

Soga, K., and S. Ikeda, Japan Kokai 75 41,996 (1975) to Tokyo Industrial University. "Polyurethanes" Chem. Abstr. 83:115389q

EI, PI, and carbon dioxide were polymerized at $0^{\circ}$; no mention of catalyst.

\section{Poly(ethylene ether-carbonate)}

Harris, R. F., J. Appl. Polymer Sci., 40, 12651279 (1990). "Effect of Catalyst on the Molecular Weight Advancement of Poly(ethylene ether carbonate) Polyols"

Sodium stannate was preferred catalyst for the polyols. Molecular weight ranges up to 3000 were attained. The reaction involves $\mathrm{CO}_{2}$ with ethylene oxide, but ether linkages are present as well as the carbonates.

\section{Polyketone-polyether}

Daniels, J. A., I. R. Stephenson, H. M. Colquhoun, and D. F. Lewis, Eur. Pat. Appl.
EP 388030 A2 (1990) to Imperial Chemical Industries. "Preparation of Aromatic Polyketones"

Polyketone-polyethers are prepared with Lewis acid catalyst, such as $\mathrm{AlCl}_{3}$, using carbon dioxide and aromatic ethers such as diphenyl ether.

\section{$\mathrm{CO}_{2}$-Silylethyne Oligomer}

Tsuda, T., H. Naoki, and S. Takeo, J. Chem. Soc., Chem. Commun., (13), 945-947 (1990). "Nickel(O)-Catalyzed Novel Cooligomerization of Ethoxy(trimethylsilyl)ethyne with Carbon Dioxide to 4,6-Diethoxy-3-(1-ethoxy-2,2bis(trimethylsilyl)vinyl)-5-(trimethylsilyl)-2pyrone"

Discussion of the synthesis of the oligomer, crystallography, and catalysts necessary for preparation.

\section{$\mathrm{CO}_{2}$-Allene Copolymer}

Sasaki, Y., J. Molecular Catal., 54, L9-L12 (1989). "Ni(O)-Catalyzed Cyclo-co-oligomerization of Allene with Carbon Dioxide"

$\mathrm{Ni}(\mathrm{COD})$ in presence of DPPE and allene was stirred at $80^{\circ} \mathrm{C}$ for $45 \mathrm{~h}$ under $15 \mathrm{~atm}$ of $\mathrm{CO}_{2}$ to give a $20 \%$ yield of the oligomer.

Note: One area not included in this bibliography involved the addition of carbon dioxide to established polymers as end groups; i.e., functionalization for specific application. This was not considered as a direct use of carbon dioxide in the backbone of the polymer. Also not included were several references to carbon dioxide functionalization into organic components using lithium derivatives. 

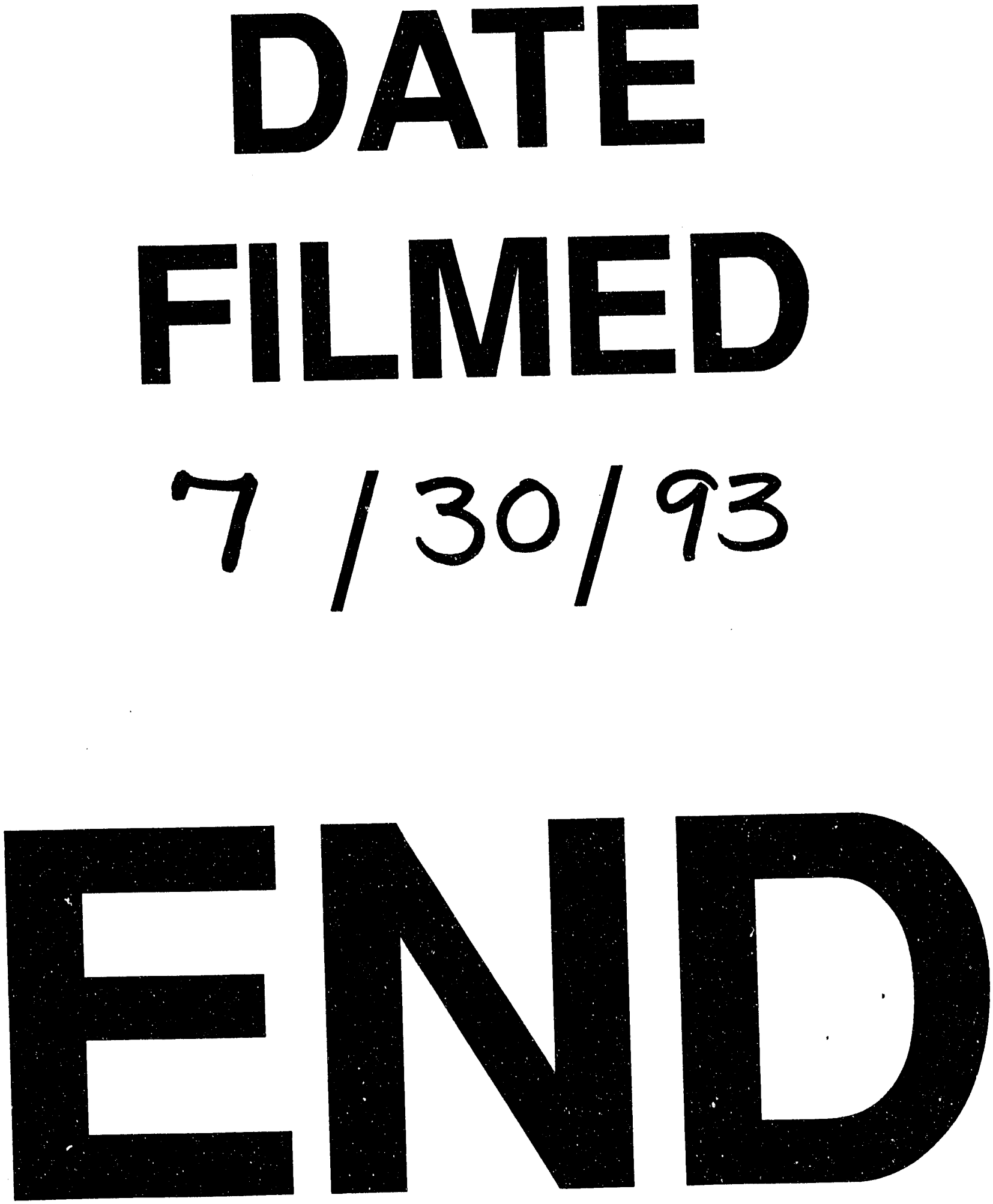